\title{
Derivatives of Cinnamic Acid Esters and Terpenic Diversity in Volatiles of Thirty-Six Sand Ginger (Kaempferia galanga L.) Accessions of Eastern India Revealing Quality Chemovars
}

\author{
Subhashree Singh, Suprava Sahoo, Bhaskar Chandra Sahoo $\mathbb{D}^{\mathrm{D}}$, Manaswini Dash, Sanghamitra Nayak \\ and Basudeba Kar*(D)
}

check for updates

Citation: Singh, S.; Sahoo, S.; Sahoo, B.C.; Dash, M.; Nayak, S.; Kar, B.

Derivatives of Cinnamic Acid Esters and Terpenic Diversity in Volatiles of Thirty-Six Sand Ginger (Kaempferia galanga L.) Accessions of Eastern India Revealing Quality Chemovars. Molecules 2022, 27, 1116. https://doi.org/10.3390/ molecules27031116

Academic Editors: William Setzer and Francesca Mancianti

Received: 18 October 2021 Accepted: 13 December 2021 Published: 8 February 2022

Publisher's Note: MDPI stays neutral with regard to jurisdictional claims in published maps and institutional affiliations.

Copyright: (c) 2022 by the authors. Licensee MDPI, Basel, Switzerland. This article is an open access article distributed under the terms and conditions of the Creative Commons Attribution (CC BY) license (https:/ / creativecommons.org/licenses/by/ $4.0 /)$.
Centre for Biotechnology, School of Pharmaceutical Sciences, Siksha 'O' Anusandhan Deemed to Be University, Kalinga Nagar, Ghatikia, Bhubaneswar 751003, Odisha, India; subhashreesingh1992@gmail.com (S.S.); supi.sos2000@gmail.com (S.S.); bhaskar.sahoo877@gmail.com (B.C.S.); dashmanaswini97@gmail.com (M.D.); sanghamitran24@gmail.com (S.N.)

* Correspondence: basu.cbt@gmail.com

\begin{abstract}
The essential oil of Kaempferia galanga L. commonly known as sand ginger has increased its demand in national and international market for decades. Cinnamic acid esters like ethyl- $p$-methoxy cinnamate (EPMC) and ethyl cinnamate (EC) are major constituents in its essential oil. In spite of the high demand for the plant as raw material, identification of quality chemovars having high essential oil (EO) yield and constituents is still at an infant stage. With this in mind, we have evaluated the EO yield of 36 accessions from three provinces of Eastern India, which varied within a range of $0.41 \pm 0.01$ to $2.63 \pm 0.03 \mathrm{v} / w$. Further, a total of 65 compounds were detected by gas chromatography and mass spectrometry (GC-MS) with area percentages varying from 76.16 to $97.3 \%$. EPMC was found to be the major component in 14 accessions with area percentages varying from $10.7 \%$ to $41.1 \%$, whereas other 22 accessions showed EC as the major constituent, varying from $16 \%$ to $29.1 \%$. Further, a diversity study among accessions was performed by agglomerative hierarchical clustering (AHC) and principal component analysis (PCA) analysis based on the abundance of identified constituents, which categorized all 36 accessions into three clusters. Thus, the present study helps to identify quality chemovar K.g16 and K.g14 with respect to oil yield and constituents, respectively, which could be used to guide commercial cultivation and further improvement of the taxa.
\end{abstract}

Keywords: Kaempferia galanga; essential oil; GC-MS; cinnamic acid esters; AHC; PCA

\section{Introduction}

Plant secondary metabolites play a significant role in the development of important drugs and cosmetics as they possess distinct physiological actions. With time, their uses have proven safety, efficacy, cultural acceptability and lesser side effects [1]. Kaempferia galanga L. (sand ginger) of the Zingiberaceae family is one such plant which has seen increased demand in the medicinal industry for decades due to the presence of bioactive secondary metabolites. Globally, K. galanga have been extensively cultivated in India, Java, Malaysia, Africa, China, and Sri Lanka [2]. In India, states such as West Bengal, Karnataka, Tamilnadu, and Kerala majorly cultivate this plant as Kapoor kachri [3,4]. According to the earlier reports, this species has biological and pharmacological activities which includes nematicidal, larvicidal, antineoplastic, and vasorelaxant effects [5-10]. Traditionally, the rhizomes and the root tubers are used for treating wounds, piles, coughs, fever, skin diseases, epilepsy, bronchitis, rheumatism, asthma, malaria, and splenic disorders. For these reasons, K. galanga rhizomes have been known as stimulant, expectorant, diuretic, carminative, antihypertensive, larvicidal, and repellent in traditional remedies [11,12].

Phytochemical studies of K. galanga essential oil have revealed the presence of multiple compounds like ethyl- $p$-methoxy cinnamate (EPMC), ethyl cinnamate (EC), $\delta$-3-carene, 
camphene, 1,8-cineole, pentadecane, borneol, etc. [13]. EPMC and EC were reported to be important bioactive constituents as these are highly cytotoxic to HeLA cells [14]. Xue and Chen [15] have also reported the anticancer properties of $K$. galanga. It has also been reported that K. galanga plant containing of EPMC inhibits resistant strains of Mycobacterium tuberculosis [16]. Such an immense curative ability of this plant enhances its significance in the medicinal industries. Due to high demand, the cost of essential oil on the global market ranges from US\$ 400-700/ $\mathrm{kg}$ [17].

Plant essential oils are complex mixture of different volatile constituents like terpenoids, phenyl polypropanoids, alkane hydrocarbons, alcohols, aldehydes, ketones, etc. which can be analyzed by gas chromatography mass spectrometry (GC-MS). This has been successfully used for characterizing chemical constituents of other different important plant essential oils [18-22]. Diverse GC-MS analyses of $K$. galanga rhizome essential oil have been reported earlier from different Asian countries on the basis of different chemovars, but in all the reports, cinnamic acid ester derivatives were identified as major constituents in rhizome essential oil that is either EC or EPMC [2,7,13,23-26].

K. galanga is one of the important medicinal plants which were included in the list of 112 medicinal herbs and spices, released by the International Standardization Organization (ISO). A lack of scientific attention and awareness have made this plant a comparatively unrecognized one $[17,27]$, but with increasing demand for this plant as a raw material, growers are gradually getting focused on cultivating quality material to enhance their livelihood. The focus on K. galanga is aimed at selecting accessions with high oil yield and quality constituents so as to provide superior raw materials [28].

Quality chemovars possess not only high oil yields but are also rich in bioactive constituents which could be used to develop value added products. Selection of such chemovars can be achieved by diversity study, as the oil yield and quality vary from place to place. Thus, diversity studies are an efficient approach towards selection of quality chemovars that can be utilized for future crop improvement. This plant can be cultivated under optimum conditions with a view to essential oil extraction for commercial purposes. The optimum environmental conditions for cultivation of K. galanga are well drained, fertile and rich moist soil. Although this wild plant grows well at elevations up to $1000 \mathrm{~m}$ in partial shade areas like open forest or forest edges with humid climate, it can also be cultivated at other regions with optimum agronomic conditions for industrial applications [29]. Identification of high yielding essential oil chemovars with quality constituents are required to meet the commercial requirements.

With all these concerns in mind, the current study was designed to select high oil yielding chemovars of $K$. galanga from three provinces (Odisha, West Bengal, Assam) of Eastern India. A diversity study with respect to EO composition of K. galanga by GC-MS analysis was also performed to explore new characteristics among the various accessions.

\section{Materials and Methods}

\subsection{Plant Material}

Thirty-six accessions of K. galanga were collected during the months of October to December in 2017 from three different provinces of Eastern India (Odisha, West Bengal, and Assam) (Figure 1). The collected accessions were identified and authenticated by a renowned taxonomist at Regional Plant Resource Center (RPRC), Bhubaneswar and Centre for Biotechnology (CBT), Siksha 'O' Anusandhan Deemed to be University, Bhubaneswar (Table 1, Figure 2). Herbarium samples of accession K.g1-20 were submitted to the Plant Taxonomy and Conservation Department, RPRC, Bhubaneswar and those of K.g21-36 were submitted to CBT, Siksha 'O' Anusandhan Deemed to be University, Bhubaneswar. 


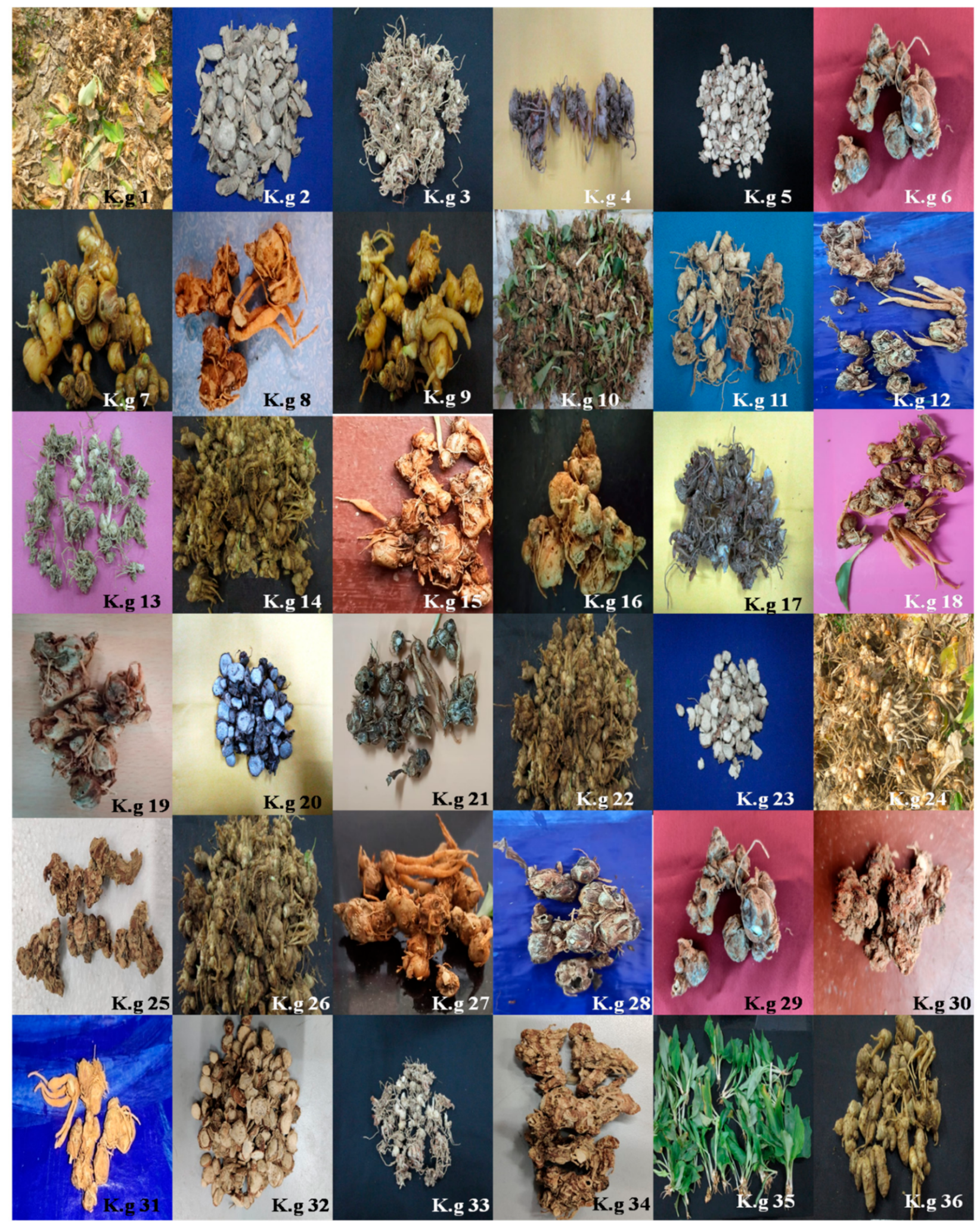

Figure 1. K. galanga collected from different locations of three provinces of Eastern India viz. Odisha, West-Bengal (W.B) and Assam. Odisha accessions-K.g1, K.g2, K.g3, K.g4, K.g14, K.g15, K.g16, K.g17, K.g18, K.g21, K.g22, K.g26, K.g27, K.g28; W.B accessions-K.g5, K.g6, K.g7, K.g8, K.g9, K.g11, K.g12, K.g13, K.g23, K.g24, K.g25, K.g29, K.g30; Assam accessions-K.g10, K.g19, K.g20, K.g31, K.g32, K.g33, K.g34, K.g35. 
Table 1. Geographical characteristics of K. galanga accessions collected from Eastern India.

\begin{tabular}{|c|c|c|c|c|c|c|c|c|c|}
\hline Accessions & Locality & Province & $\begin{array}{l}\text { Voucher } \\
\text { Specimen }\end{array}$ & $\begin{array}{l}\text { Longitude } \\
\text { (E) }\end{array}$ & $\begin{array}{l}\text { Lattitude } \\
(\mathrm{N})\end{array}$ & $\begin{array}{l}\text { Altitude } \\
(\mathrm{m})\end{array}$ & $\begin{array}{l}\mathrm{T}_{\max } \\
\left({ }^{\circ} \mathrm{C}\right)\end{array}$ & $\begin{array}{l}\mathrm{T}_{\min } \\
\left({ }^{\circ} \mathrm{C}\right)\end{array}$ & $\begin{array}{c}\text { A.A.P * } \\
(\mathrm{mm})\end{array}$ \\
\hline K.g1 & Barunei & Odisha & 11,053 & $85^{\circ} 38^{\prime} 40^{\prime \prime}$ & $20^{\circ} 10^{\prime} 39^{\prime \prime}$ & 109 & 34.5 & 21.9 & 1500 \\
\hline K.g2 & Jagatpur & Odisha & 11,054 & $85^{\circ} 36^{\prime} 02^{\prime \prime}$ & $20^{\circ} 27^{\prime} 52^{\prime \prime}$ & 40 & 32.6 & 21.9 & 1515 \\
\hline K.g3 & Patrapada & Odisha & 11,055 & $85^{\circ} 45^{\prime} 37^{\prime \prime}$ & $20^{\circ} 14^{\prime} 34^{\prime \prime}$ & 47 & 31.7 & 21.9 & 1505 \\
\hline K.g4 & Berhampur & Odisha & 11,056 & $84^{\circ} 47^{\prime} 00^{\prime \prime}$ & $19^{\circ} 18^{\prime} 15^{\prime \prime}$ & 25 & 29.7 & 22 & 1194 \\
\hline K.g5 & Jalangi & West Bengal & 11,057 & $88^{\circ} 41^{\prime} 26^{\prime \prime}$ & $24^{\circ} 7^{\prime} 41^{\prime \prime}$ & 473 & 29.6 & 18.6 & 1459 \\
\hline K.g6 & Domkol & West Bengal & 11,058 & $88^{\circ} 32^{\prime} 49^{\prime \prime}$ & $24^{\circ} 7^{\prime} 31^{\prime \prime}$ & 23 & 25.4 & 22.8 & 1530 \\
\hline K.g7 & Krishnanagar & West Bengal & 11,062 & $88^{\circ} 28^{\prime} 55^{\prime \prime}$ & $23^{\circ} 24^{\prime} 04^{\prime \prime}$ & 19 & 30.9 & 18.9 & 1353 \\
\hline K.g8 & Karimpur & West Bengal & 11,059 & $88^{\circ} 33^{\prime} 24^{\prime \prime}$ & $23^{\circ} 28^{\prime} 15^{\prime \prime}$ & 10 & 30 & 18.6 & 1434 \\
\hline K.g9 & Narendrapur & West Bengal & 11,063 & $88^{\circ} 23^{\prime} 57^{\prime \prime}$ & $22^{\circ} 26^{\prime} 25^{\prime \prime}$ & 9 & 30.3 & 19.6 & 1645 \\
\hline K.g10 & Narayanpur & Assam & 11,064 & $93^{\circ} 49^{\prime} 58^{\prime \prime}$ & $26^{\circ} 56^{\prime} 31^{\prime \prime}$ & 83 & 32 & 20.8 & 1518 \\
\hline K.g11 & Berhampore & West Bengal & 11,065 & $85^{\circ} 14^{\prime} 59^{\prime \prime}$ & $20^{\circ} 05^{\prime} 40^{\prime \prime}$ & 23 & 30.7 & 18.7 & 1347 \\
\hline K.g12 & Kalimpong & West Bengal & 11,066 & $88^{\circ} 27^{\prime} 21^{\prime \prime}$ & $27^{\circ} 04^{\prime} 13^{\prime \prime}$ & 1067 & 22.1 & 12 & 2395 \\
\hline K.g13 & Sargachi & West Bengal & 11,067 & $88^{\circ} 14^{\prime} 58^{\prime \prime}$ & $24^{\circ} 01^{\prime} 17^{\prime \prime}$ & 24 & 30.7 & 18.8 & 1365 \\
\hline K.g14 & Jeypore & Odisha & 11,068 & $82^{\circ} 34^{\prime} 07^{\prime \prime}$ & $18^{\circ} 53^{\prime} 00^{\prime \prime}$ & 592 & 30.3 & 19 & 1587 \\
\hline K.g15 & Astaranga & Odisha & 11,069 & $86^{\circ} 16^{\prime} 12^{\prime \prime}$ & $19^{\circ} 58^{\prime} 48^{\prime \prime}$ & 8 & 29.7 & 22.1 & 1337 \\
\hline K.g16 & Daringbadi & Odisha & 11,070 & $84^{\circ} 7^{\prime} 60^{\prime \prime}$ & $19^{\circ} 53^{\prime} 60^{\prime \prime}$ & 914 & 32 & 4 & 1176.1 \\
\hline K.g17 & Phulbani & Odisha & 11,071 & $84^{\circ} 14^{\prime} 47^{\prime \prime}$ & $20^{\circ} 28^{\prime} 31^{\prime \prime}$ & 26 & 31.6 & 19 & 1323 \\
\hline K.g18 & Parelakhemundi & Odisha & 11,072 & $84^{\circ} 05^{\prime} 55^{\prime \prime}$ & $18^{\circ} 50^{\prime} 4^{\prime \prime}$ & 145 & 46 & 10 & 1925.6 \\
\hline K.g19 & Chariali & Assam & 11,073 & $91^{\circ} 44^{\prime} 45^{\prime \prime}$ & $26^{\circ} 10^{\prime} 20^{\prime \prime}$ & 51 & 39.5 & 14.1 & 2054 \\
\hline K.g20 & Jorhat & Assam & 11,075 & $94^{\circ} 13^{\prime} 12^{\prime \prime}$ & $26^{\circ} 45^{\prime} 0^{\prime \prime}$ & 116 & 28.9 & 16.6 & 2324 \\
\hline K.g21 & Similipal & Odisha & 1018/CBT & $86^{\circ} 15^{\prime} 26^{\prime \prime}$ & $21^{\circ} 51^{\prime} 41^{\prime \prime}$ & 622 & 32.4 & 20.2 & 1596 \\
\hline K.g22 & Paikamal & Odisha & $1019 / \mathrm{CBT}$ & $82^{\circ} 48^{\prime} 45^{\prime \prime}$ & $20^{\circ} 55^{\prime} 18^{\prime \prime}$ & 273 & 35.2 & 20.4 & 1435 \\
\hline K.g23 & Lataguri & West Bengal & $1020 / \mathrm{CBT}$ & $88^{\circ} 46^{\prime} 49^{\prime \prime}$ & $26^{\circ} 43^{\prime} 10^{\prime \prime}$ & 123 & 27.9 & 16.9 & 3242 \\
\hline K.g24 & Lalbagh & West Bengal & 1021/CBT & $88^{\circ} 16^{\prime} 10^{\prime \prime}$ & $24^{\circ} 09^{\prime} 39^{\prime \prime}$ & 24 & 29.8 & 18.4 & 1343 \\
\hline K.g25 & Rahara & West Bengal & $1022 / \mathrm{CBT}$ & $88^{\circ} 23^{\prime} 13^{\prime \prime}$ & $22^{\circ} 43^{\prime} 33^{\prime \prime}$ & 12 & 30.5 & 19.5 & 1569 \\
\hline K.g26 & Basantapur & Odisha & $1023 / \mathrm{CBT}$ & $84^{\circ} 48^{\prime} 52^{\prime \prime}$ & $21^{\circ} 03^{\prime} 04^{\prime \prime}$ & 215 & 30.6 & 18.7 & 1540 \\
\hline K.g27 & Agarpada & Odisha & $1024 / \mathrm{CBT}$ & $86^{\circ} 20^{\prime} 30^{\prime \prime}$ & $21^{\circ} 12^{\prime} 36^{\prime \prime}$ & 42 & 31.9 & 20.6 & 1530 \\
\hline K.g28 & Chhatia & Odisha & $1025 / \mathrm{CBT}$ & $86^{\circ} 03^{\prime} 21^{\prime \prime}$ & $20^{\circ} 36^{\prime} 34^{\prime \prime}$ & 39 & 31.9 & 21.1 & 1519 \\
\hline K.g29 & Sainthia & West Bengal & 1026/CBT & $87^{\circ} 40^{\prime} 03^{\prime \prime}$ & $23^{\circ} 56^{\prime} 59^{\prime \prime}$ & 50 & 31 & 18.7 & 1328 \\
\hline K.g30 & Digha & West Bengal & $1027 / \mathrm{CBT}$ & $87^{\circ} 31^{\prime} 04^{\prime \prime}$ & $21^{\circ} 37^{\prime} 235^{\prime \prime}$ & 11 & 30.8 & 20.4 & 1519 \\
\hline K.g31 & Napaam & Assam & $1028 / \mathrm{CBT}$ & $92^{\circ} 49^{\prime} 31^{\prime \prime}$ & $26^{\circ} 42^{\prime} 14^{\prime \prime}$ & 73 & 28.8 & 17.5 & 1836 \\
\hline K.g32 & Thelamara & Assam & $1029 / \mathrm{CBT}$ & $92^{\circ} 35^{\prime} 09^{\prime \prime}$ & $26^{\circ} 41^{\prime} 40^{\prime \prime}$ & 77.1 & 28.9 & 17.3 & 1903 \\
\hline K.g33 & Tanganapara & Assam & $1030 / \mathrm{CBT}$ & $94^{\circ} 33^{\prime} 26^{\prime \prime}$ & $27^{\circ} 28^{\prime} 21^{\prime \prime}$ & 106 & 29 & 17.2 & 2111 \\
\hline K.g34 & Nilpur & Assam & $1031 / \mathrm{CBT}$ & $93^{\circ} 08^{\prime} 30^{\prime \prime}$ & $26^{\circ} 43^{\prime} 37^{\prime \prime}$ & 83.8 & 29 & 17.2 & 2326 \\
\hline K.g35 & Chinatoli & Assam & $1032 / \mathrm{CBT}$ & $93^{\circ} 59^{\prime} 18^{\prime \prime}$ & $26^{\circ} 29^{\prime} 06^{\prime \prime}$ & 102.4 & 29 & 16.6 & 2782 \\
\hline K.g36 & Athagarh & Odisha & $1033 / \mathrm{CBT}$ & $85^{\circ} 37^{\prime} 51^{\prime \prime}$ & $20^{\circ} 31^{\prime} 06^{\prime \prime}$ & 63 & 32.2 & 21.4 & 1484 \\
\hline
\end{tabular}

Note: * AAP—Average annual precipitation.

\subsection{Essential Oil Extraction}

The rhizomes of $K$. galanga were shade dried and $100 \mathrm{~g}$ from each accession were taken for essential oil (EO) isolation by a hydro-distillation method. The process was conducted using a Clevenger-type apparatus for a period of 3-4 h. Further, the EOs were treated with anhydrous sodium sulfate to remove any water content. The purified EOs were then stored in amber glass vials at $4{ }^{\circ} \mathrm{C}$ until further analysis. EO isolations from each accession were performed in triplicate to confirm the yield reproducibility. EO yield was calculated on dry weight basis and statistical analysis has been carried out to understand the significance of variation. Analysis of variance (ANOVA) and Tukey's honestly significant difference (HSD) test at $p<0.05$ were carried using the Minitab 17 statistical software (Minitab Inc., State College, PA, USA).

\subsection{GC-MS Analysis}

K. galanga essential oils of different accessions were analyzed using GC-MS. Thiswas performed using a Clarus 580 gas chromatograph (Perkin Elmer Inc., Waltham, MA, USA) equipped with a SQ8S mass spectrometry detector. Helium was used as the mobile phase at a flow rate of $1 \mathrm{ml} / \mathrm{min}$. Neat oil $(0.1 \mu \mathrm{L})$ was injected into the system for performing 
the analyses. The column used was an Elite- 5 column ( $30 \mathrm{~m}$ length with $0.25 \mathrm{~mm}$ internal diameter and $0.25 \mu \mathrm{m}$ of film thickness). Initially, the oven temperature was set at $60^{\circ} \mathrm{C}$ for $1 \mathrm{~min}$ and then heated at $3{ }^{\circ} \mathrm{C} / \mathrm{min}$ to $220^{\circ} \mathrm{C}$ with a $6 \mathrm{~min}$ hold period. The total runtime was $60 \mathrm{~min}$. The transfer interface and source temperatures were set at $250{ }^{\circ} \mathrm{C}$ and $150{ }^{\circ} \mathrm{C}$, respectively. Scanning was performed over a mass scan range of 50-600 amu with EI mode at an ionization voltage of $70 \mathrm{eV}$. Turbo Mass TM software 6.1.0 (PerkinElmer Inc.) was used for acquiring the ion chromatogram and mass spectra. Retention Index (RI) was calculated by determining RT (Retention Time) of straight chain $n$-alkanes (Sigma Aldrich, St. Louis, $\mathrm{MO}$, USA) with similar operating conditions. The mass spectra of detecting compounds were compared with the inbuilt NIST/EPA/NIH mass spectra library (NIST 11). The identified compounds were further validated by comparing RI values obtained from the experiment with data reported in the literature and Adams library [30]. EPMC (Cayman Chemicals, Ann Arbor, MI, USA) and EC (Sigma Aldrich) standards were injected in GC-MS to authenticate the identification of both compounds in all accessions. Both the standards $(0.1 \mu \mathrm{L})$ were injected into the system while keeping all parameters the same as for the analytes.

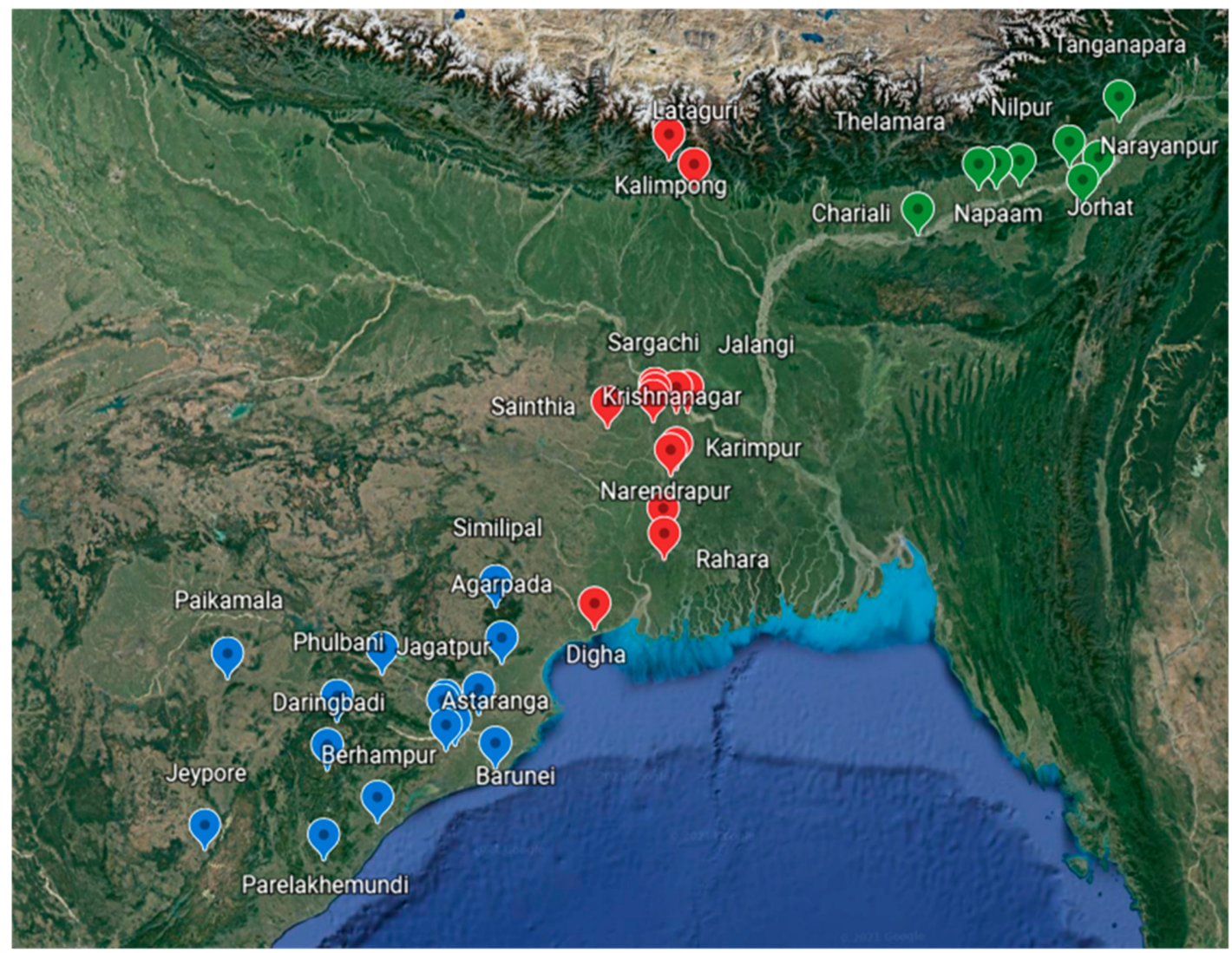

Figure 2. Map showing different regions of sample collection from Eastern India (Blue tags-Odisha provinces, red tags-West-Bengal provinces, green tags-Assam provinces).

\subsection{Statistical Analysis}

To correlate the similarity and relationship between different accessions of K. galanga, agglomerative hierarchical clustering (AHC) and principal component analysis (PCA) were accomplished using Minitab 17 statistical software. Constituents having area percentages greater than $1 \%$ were considered for both the analysis. For AHC, Pearson distance was calculated in accordance with the Ward linkage variance minimizing method towards analyzing linear correlation among samples for hierarchical clustering [31]. To accomplish the PCA, the correlation matrix was resolved, which transformed 15 variables into 15 principal components (PCs) [32]. Eigen values of the principal components are the constants 
that increase or decrease the eigenvectors (variance) along its span when transformed linearly. The variables that are being used in PCs are taken as loadings and the individual transformed observations are as scores.

\section{Result and Discussion}

\subsection{Essential Oil Extraction}

The essential oils from 36 accessions of K. galanga rhizomes were isolated and the mean oil yield was evaluated by using one way ANOVA followed by Tukey's HSD test at a confidence interval of $95 \%$. The oil yield varied within a range of $0.41 \pm 0.01 \%-2.63 \pm 0.03 \%$ on a dry weight basis (Table 2) The highest oil yield was found to be in the K.g16 (2.63 $\pm 0.03 \%$ $v / w)$ accession, whereas the lowest oil yield $(0.41 \pm 0.01 \% v / w)$ was obtained for the K.g15 accession. The K.g16 chemovar with the highest essential oil yield was collected from Daringbadi (Kandhamala District, Odisha) at $914 \mathrm{~m}$ altitude, where the annual average rainfall is $1176.1 \mathrm{~mm}$ and temperature varies from $4-32^{\circ} \mathrm{C}$.

Table 2. Essential oil yield percentage of K. galanga from different accessions.

\begin{tabular}{|c|c|c|c|}
\hline Accessions & Province & Locality & Oil Yield $(\%)\left(\right.$ Mean \pm SD) ${ }^{a}$ \\
\hline K.g1 & Odisha & Barunei & $0.65 \pm 0.03$ \\
\hline K.g2 & Odisha & Jagatpur & $1.5 \pm 0.03$ \\
\hline K.g3 & Odisha & Patrapada & $0.63 \pm 0.04$ \\
\hline K.g4 & Odisha & Berhampur & $0.84 \pm 0.04$ \\
\hline K.g5 & West Bengal & Jalangi & $2.41 \pm 0.01$ \\
\hline K.g6 & West Bengal & Domkol & $1.84 \pm 0.05$ \\
\hline K.g7 & West Bengal & Krishnanagar & $1.63 \pm 0.03$ \\
\hline K.g8 & West Bengal & Karimpur & $2.41 \pm 0.04$ \\
\hline K.g9 & West Bengal & Narendrapur & $2.35 \pm 0.02$ \\
\hline K.g10 & Assam & Lakhimpur & $0.92 \pm 0.02$ \\
\hline K.g11 & West Bengal & Berhampore & $0.51 \pm 0.01$ \\
\hline K.g12 & West Bengal & Kalimpong & $1.92 \pm 0.16$ \\
\hline K.g13 & West Bengal & Sargachi & $0.84 \pm 0.05$ \\
\hline K.g14 & Odisha & Jeypore & $2.3 \pm 0.01$ \\
\hline K.g15 & Odisha & Astaranga & $0.41 \pm 0.01$ \\
\hline Kg16 & Odisha & Daringbadi & $2.63 \pm 0.03$ \\
\hline K.g17 & Odisha & Phulbani & $1.33 \pm 0.03$ \\
\hline K.g18 & Odisha & Parelakhemundi & $0.76 \pm 0.03$ \\
\hline K.g19 & Assam & Chariali & $1.22 \pm 0.02$ \\
\hline K.g20 & Assam & Jorhat & $1.83 \pm 0.03$ \\
\hline K.g21 & Odisha & Similipal & $2.03 \pm 0.06$ \\
\hline K.g22 & Odisha & Paikamal & $1.63 \pm 0.03$ \\
\hline K.g23 & West Bengal & Lataguri & $1.23 \pm 0.04$ \\
\hline K.g24 & West Bengal & Lalbagh & $1.43 \pm 0.02$ \\
\hline K.g25 & West Bengal & Rahara & $1.22 \pm 0.03$ \\
\hline K.g26 & Odisha & Basantapur & $0.82 \pm 0.06$ \\
\hline K.g27 & Odisha & Agarpada & $1.24 \pm 0.03$ \\
\hline K.g28 & Odisha & Chhatia & $1.77 \pm 0.1$ \\
\hline K.g29 & West Bengal & Sainthia & $1.88 \pm 0.01$ \\
\hline K.g30 & West Bengal & Digha & $1.77 \pm 0.02$ \\
\hline K.g31 & Assam & Napaam & $2.01 \pm 0.02$ \\
\hline K.g32 & Assam & Thelamara & $1.98 \pm 0.03$ \\
\hline K.g33 & Assam & Tanganapara & $1.32 \pm 0.03$ \\
\hline K.g34 & Assam & Nilpur & $1.26 \pm 0.03$ \\
\hline K.g35 & Assam & Chinatoli & $1.31 \pm 0.04$ \\
\hline K.g36 & Odisha & Athagarh & $1.82 \pm 0.05$ \\
\hline
\end{tabular}

${ }^{\mathrm{a}}$ Mean \pm standard deviation (SD).

The oil yield of K. galanga in this current study was higher than in previous reports about India $[13,25,33$ ]. Raina et al., reported oil yields ranging from 0.3 to $1.9 \%$ and 0.83 to $2.19 \%$ for samples collected from different districts of Southern Western Ghats in Karnataka and Kerala states, respectively [13]. A new accession from the North East region having 
a yield of $2.38 \%$ on average has also been reported. Similarly, in other Asian countries variations in oil yield have also been reported, with highest yield reported so far being $2 \%[25,33]$. The grouping of the accessions denotes that there were significant variations in oil yield among different accessions on the basis of different geographical locations (Table 2). There are several factors which are responsible for the variation in essential oil production like seasonal variation, mechanical or chemical injuries, geographical variation and environmental factors [34]. The accessions taken in this study were all collected at the beginning of the winter season that is from October-December 2017, hence seasonal variation has less chance of causing EO yield variations. Other factors mentioned above could be collectively responsible for the same. A higher range of altitudes plays an important role as well in varied EO yield, as reported for many species like Hedychium coronarium, Zingiber zerumbet, Curcuma longa, Zingiber officinale, Myristica fragans, etc. [34-37]. K.g16 having the highest essential oil yield with quality constituents could be used for large scale cultivation and subsequently for commercial production of essential oil.

\subsection{GC-MS Analysis}

The phyto-constituents of K. galanga EOs were analyzed by GC-MS and a total of 65 compounds were detected. The area percentages of all identified constituents in different accessions fall within the range of 76.16-98.9\%. In all accessions, phenyl polypropanoids (EPMC and EC) constituted the major components, varying from 39.26 to $69 \%$. In Odisha accessions, the abundance of phenyl polypropanoids was high (43.17-69\%) followed by monoterpene hydrocarbons (5.8-21.21\%), alkane hydrocarbons (1.2-15.19\%), oxygenated monoterpenes (3.53-11.38\%), sesquiterpenes hydrocarbon $(2.8-4.2 \%)$ and oxygenated sesquiterpenes (0.17-1.84\%) (Table S1a from Supplementary Materials). Similarly in West-Bengal samples phenyl polypropanoids represent the major area percentages $(39.26-55 \%)$, followed by alkane hydrocarbons $(7.14-25.64 \%)$, monoterpene hydrocarbons (12.43-21.82\%), oxygenated monoterpenes $(2.73-10.75 \%)$, sesquiterpene hydrocarbons $(1.72-4.44 \%)$ and oxygenated sesquiterpenes $(0.09-3.44 \%$ ) (Table S1b from Supplementary Materials). Likewise, in Assam accessions the abundance of phenyl polypropanoids was also high (40.97-47.11\%), followed by monoterpene hydrocarbons (15.32-22.14\%), alkane hydrocarbons (8.14-14.52\%) and oxygenated monoterpenes (5.01-8.08\%), sesquiterpene hydrocarbons (1.54-4.01\%) and oxygenated sesquiterpenes (0.3-1.25\%) (Figure 3; Table S1c from Supplementary Materials).

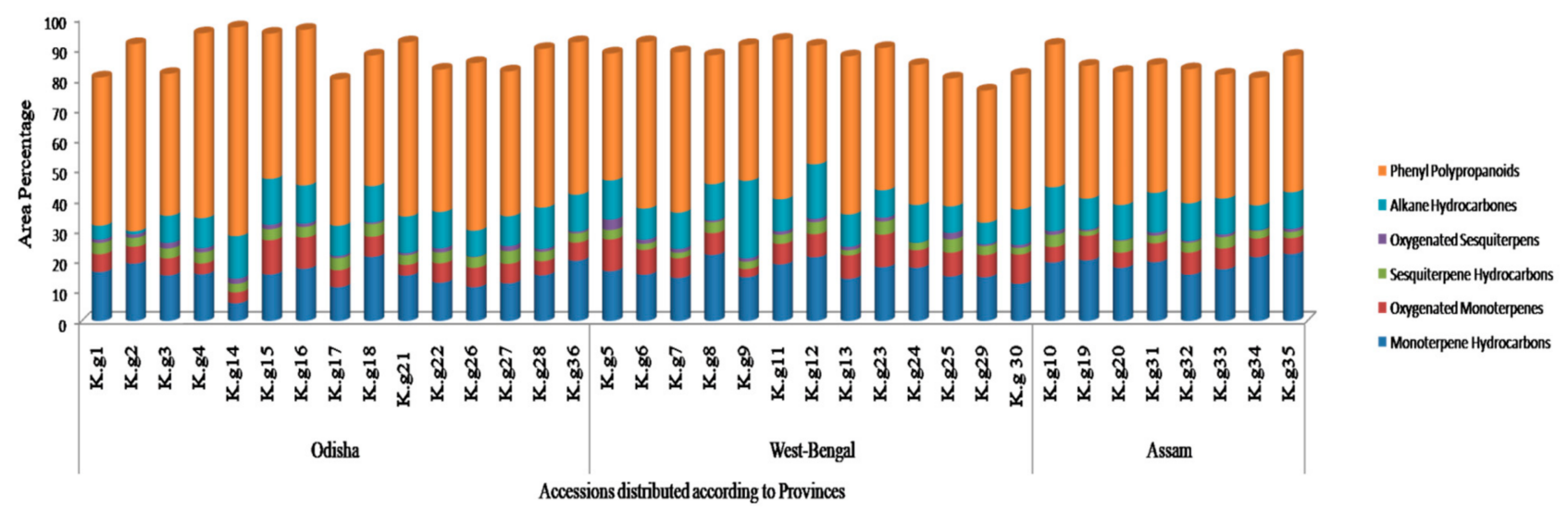

Figure 3. Classification of different group of compounds based on their abundance (area \%) present in essential oil of K. galanga rhizomes collected from three different provinces.

Accessions of Odisha province were rich in EPMC (20.14-41.13\%) as major constituent in almost all accessions, except K.g16 and K.g18 where EC (14.9-29.9\%) was found to be the major one. The other top constituents were pentadecane (1-14.7\%) $\delta$-carene (1.31-12.28\%), 1,8-cineole (1.51-7.13\%) etc. (Table 3a and Table S1a from Supplementary Materials). Among West Bengal provinces, all accessions except K.g5 contained EC (20.9-29.14\%) 
as the major constituent, followed by EPMC (10.7-27\%), pentadecane (7.14-24.93\%), $\delta$ carene (5.87-12.28\%) 1,8-cineole (2.09-6.54\%), etc. (Table 3b and Table S1b from Supplementary Materials). All the accessions of the Assam region have EC (21.54-26\%) as the major constituent, followed by EPMC (17.16-22.21\%), pentadecane (8.14-14.52\%), $\delta$-carene (7.1-11.76\%), 1,8-cineole (3.21-5.21\%), etc. (Table 3c and Table S1c from Supplementary Materials). Standards of EPMC and EC were injected for authentic identification of these two major bioactive constituents in all samples. The GC chromatograms of two standards gave peaks at retention times (RT) of 37.32 and RT 26.35, respectively (Figure S1 from Supplementary Materials). Structures of all identified constituents have been indicated in the Supplementary Materials (Table S2). In this study, the chemical compositions identified in rhizome EO of K. galanga accessions closely resembled earlier reports on same plant from Malaysia [33], Sri Lanka [38], and India [23]. All accessions of K. galanga have cinnamic acid esters as major constituents and were more or less similar to each other with respect to other chemical constituents. However, significant variations were found with respect to the area percentages of the constituents. A similar pattern of findings has also been reported in other studies where the major constituent was either EC or EPMC or their trans isomers like ethyl trans-cinnamate, ethyl trans-p-methoxy cinnamate and methyl cinnamate $[2,10,13,26]$.

Higher abundance of EPMC is one of the important criteria towards selection of quality chemovars as it is a highly active constituent with cytotoxic, proapoptotic, antiinflammatory, analgesic, anti-neoplastic, and anti-oxidant like activities [24,39]. Similarly the abundance of bioactive constituent $\mathrm{EC}$ has almost equal importance in the selection of quality chemovars. In this study, GC-MS analysis revealed two important chemovars, K.g16-EPMC and K.g14-EC (Figure 4a,b). However, other constituents were also identified and mentioned in Table S1. The GC-MS peaks of all accessions were merged to develop a consensus fingerprint towards confirming the authenticity of accessions collected from different provinces (Figure 4c). The consensus GC-MS chromatogram could be used to check for adulteration in K. galanga rhizome essential oil.
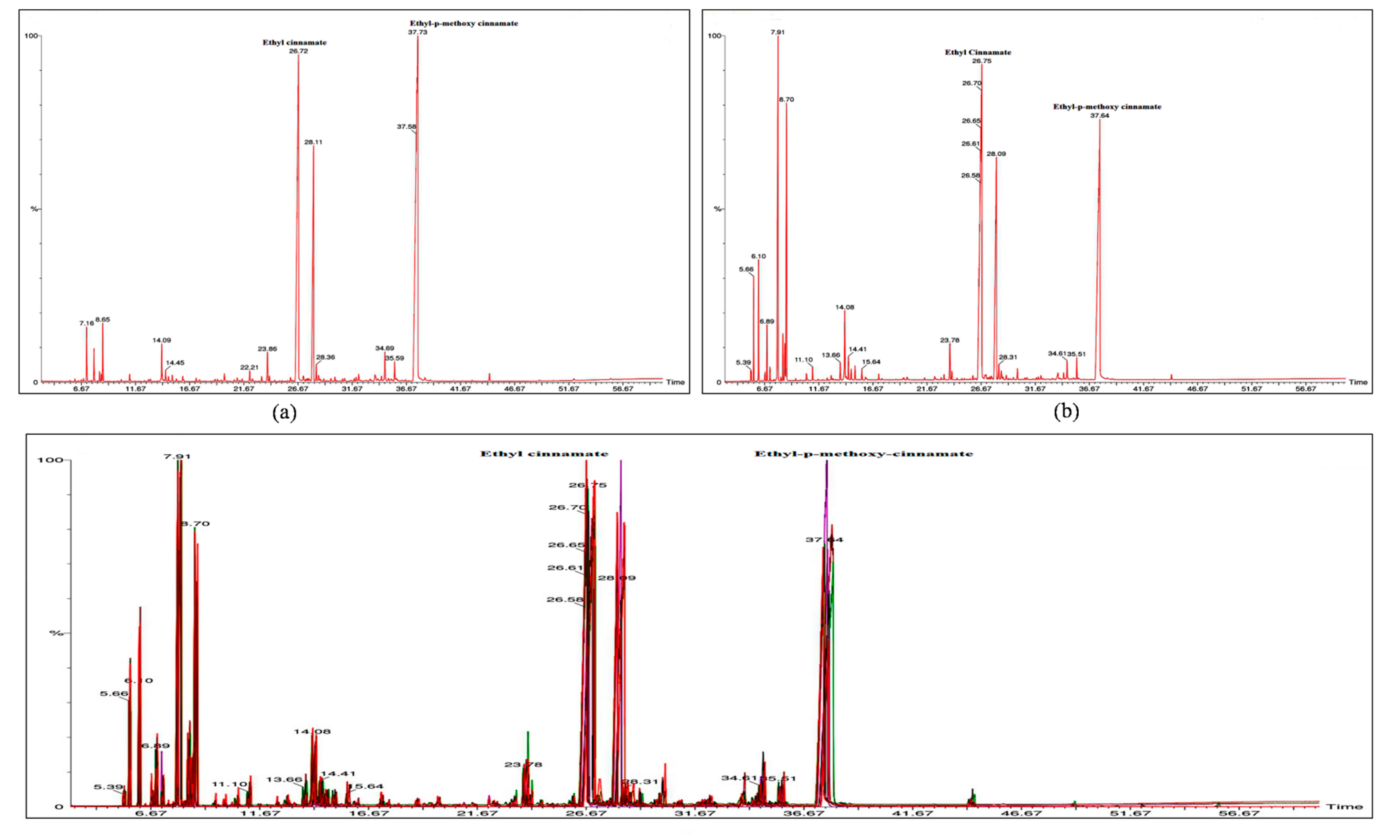

(c)

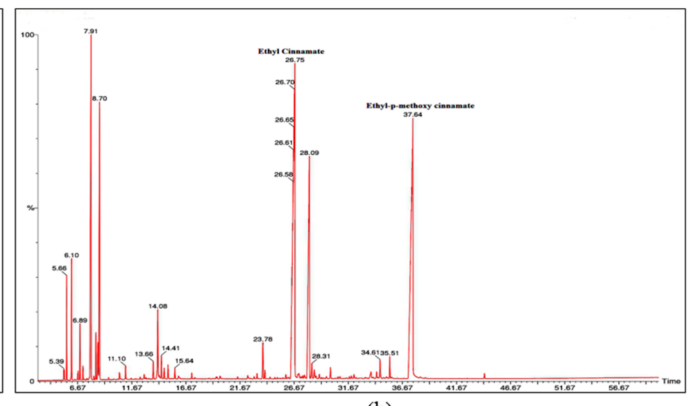

(b)

Figure 4. GC-MS chromatogram of K. galanga rhizome essential oil with different constituents. (a) Chromatogram of K.g14 showing EPMC as major constituent and EC as second major constituent (b) Chromatogram of K.g16 showing EC as major constituent and EPMC as second major constituent (c) Consensus GC-MS fingerprint of K. galanga accessions collected from three different provinces showing similar pattern. 
Table 3. Major constituents (GC area\% $\geq 1$ ) of $K$. galanga rhizome essential oil collected from different locations of (a) Odisha province, (b) West-Bengal province, (c) Assam province.

\begin{tabular}{|c|c|c|c|c|c|c|c|c|c|c|c|c|c|c|c|c|c|c|}
\hline \multicolumn{19}{|c|}{ (a) } \\
\hline \multirow{2}{*}{ S1 No. } & \multirow{2}{*}{ Compound } & \multirow{2}{*}{$\mathbf{R I}^{\mathrm{a}}$} & \multirow{2}{*}{$\mathbf{R I}^{\mathbf{b}}$} & \multicolumn{15}{|c|}{ Odisha } \\
\hline & & & & K.g1 & K.g2 & K.g3 & K.g4 & K.g14 & K.g15 & K.g16 & K.g17 & K.g18 & K.g21 & K.g22 & K.g26 & K.g27 & K.g28 & K.g36 \\
\hline 1 & $\alpha$-Pinene & 932 & 932 & 1.3 & 1.91 & 1.1 & 1.19 & 1 & 1.7 & 1.53 & 2.1 & 2.1 & 1 & 1.3 & 1.25 & 1.45 & 1.2 & 1.31 \\
\hline 2 & Camphene & 949 & 946 & 1.49 & 3.03 & 1.58 & 1.86 & 1 & 3.07 & 1.97 & 1.12 & 2.59 & 1.9 & 1.01 & 2.04 & 1.76 & 1.25 & 3.15 \\
\hline 3 & $\delta$-Carene & 1011 & 1008 & 8.59 & 10.9 & 8.28 & 9.64 & 1.31 & 7.87 & 9.97 & 5.1 & 12.28 & 9.37 & 6.5 & 5.12 & 3.17 & 8.56 & 10.06 \\
\hline 4 & Limonene & 1028 & 1024 & 1.14 & 1.09 & 1.09 & 1.13 & 1 & 1.04 & 1 & 1 & 1.14 & 1.8 & 1.76 & 1 & 1.41 & 1.64 & 1.67 \\
\hline 5 & 1,8-Cineole & 1032 & 1026 & 3.23 & 3.64 & 3.08 & 2.37 & 1.51 & 6.03 & 7.13 & 3.76 & 5.35 & 1.62 & 4.12 & 3.17 & 4.13 & 2.09 & 4.12 \\
\hline 6 & Borneol & 1170 & 1165 & 1 & 1.54 & 1.07 & 1.23 & 1.19 & 2.38 & 1.9 & 1.23 & 1.29 & 1.11 & 1 & 2.31 & 1.16 & 2.07 & 1.19 \\
\hline 7 & $\beta$-Elemene & 1383 & 1389 & 0.33 & - & 0.68 & - & 0.16 & - & 1.03 & 0.99 & - & - & 0.89 & - & - & - & - \\
\hline 9 & $n$-Tetradecane & 1396 & 1400 & 0.23 & - & 0.2 & - & 1.03 & - & 0.22 & - & - & - & 0.76 & - & - & 0.13 & 0.12 \\
\hline 10 & $\alpha$-Gurjunene & 1402 & 1409 & 0.54 & 0.26 & 0.2 & 0.64 & 0.17 & 0.9 & - & 0.88 & 0.26 & 0.95 & - & 1.01 & 0.87 & 1 & 0.67 \\
\hline 11 & Ethyl Cinnamate & 1467 & 1465 & 14.9 & 28 & 18.87 & 22.31 & 27.9 & 19 & 29.7 & 17.12 & 23.03 & 27.27 & 18.98 & 24.41 & 19.09 & 21.02 & 17.98 \\
\hline 12 & Germacrene D & 1673 & 1484 & 1.07 & 1.06 & 1.16 & 1.17 & 1 & 1.11 & 1.21 & 1 & 1.31 & 1.16 & 1.6 & 1.5 & 1.87 & 1 & 1 \\
\hline 13 & Pentadecane & 1504 & 1500 & 4.33 & 1 & 8.42 & 9.94 & 12.4 & 14.7 & 11.9 & 9.87 & 11.98 & 12.1 & 10.89 & 8.59 & 9.87 & 13.54 & 12.1 \\
\hline 14 & 8,9 Epoxide Cadalene & 1677 & 1674 & 0.29 & - & 0.49 & - & 1 & 0.59 & - & - & - & - & - & - & - & - & - \\
\hline 15 & Ethyl $p$-Methoxycinnamate & 1769 & 1760 & 31.8 & 33.9 & 25.36 & 38.79 & 41.13 & 29 & 25.35 & 31.25 & 20.14 & 30.26 & 27.32 & 30.98 & 28.76 & 31.41 & 32.4 \\
\hline \multicolumn{19}{|c|}{ (b) } \\
\hline S1 No. & Compound & $\mathbf{R I}^{\mathrm{a}}$ & $\mathbf{R I}^{\mathbf{b}}$ & \multicolumn{15}{|c|}{ West-Bengal } \\
\hline 1 & $\alpha$-Pinene & 932 & 932 & 1.57 & 1 & 1.01 & 2.1 & 1 & 1.66 & 1.81 & 1.77 & 1.98 & 1.68 & 1.89 & \multicolumn{2}{|c|}{1.09} & \multicolumn{2}{|c|}{1.78} \\
\hline 2 & Camphene & 949 & 946 & 2.67 & 1.14 & 1.2 & 2.59 & 1.9 & 2.57 & 2.63 & 2.75 & 3.71 & 2.4 & 2.18 & \multicolumn{2}{|c|}{1.21} & \multicolumn{2}{|c|}{1.32} \\
\hline 3 & $\beta$-Pinene & 977 & 974 & 0.62 & 0.34 & 0.35 & 1.01 & 0.3 & 0.84 & 1.01 & 0.72 & 1.09 & 0.14 & 1.2 & \multicolumn{2}{|c|}{1} & \multicolumn{2}{|c|}{0.89} \\
\hline 4 & $\delta$-Carene & 1011 & 1008 & 8.29 & 10 & 9.9 & 12.28 & 9.37 & 10.38 & 11.98 & 6.91 & 7.09 & 10.09 & 5.87 & \multicolumn{2}{|c|}{8.67} & \multicolumn{2}{|c|}{6.32} \\
\hline 5 & $p$-Cymene & 1021 & 1020 & 1.42 & 1.39 & 1 & 1.24 & 1.24 & 1.38 & 1 & 1.14 & 1.08 & 1 & 1 & & & & \\
\hline 6 & $o$-Cymene & 1023 & 1022 & - & - & - & 1.2 & - & - & 0.84 & - & - & - & - & & & & \\
\hline 7 & Limonene & 1028 & 1024 & 0.96 & 0.65 & 0.45 & 0.14 & 0.35 & 0.15 & 0.2 & 0.32 & 0.98 & 0.87 & 0.76 & & & & \\
\hline 8 & 1,8-Cineole & 1032 & 1026 & 4.44 & 5 & 4 & 5.35 & 1.62 & 4.82 & 5.42 & 3.56 & 6.14 & 2.09 & 3.21 & & & & \\
\hline 9 & Borneol & 1170 & 1165 & 1.8 & 1.01 & 1 & 1.82 & 1.11 & 1.81 & 2 & 1.54 & 1.89 & 1.6 & 2.19 & & & & \\
\hline 10 & $\alpha$-Terpinyl Acetate & 1350 & 1346 & 1.01 & 1 & 1 & - & - & - & - & 0.98 & 1.08 & 1.01 & 0.14 & & & & \\
\hline 11 & $\alpha$-Gurjunene & 1402 & 1409 & 1.19 & 1 & 1 & 1.01 & 1 & 1.31 & 1.16 & 1.03 & 1.12 & 1.04 & 1 & & & & \\
\hline 12 & Ethyl Cinnamate & 1467 & 1465 & 20.9 & 28 & 27 & 23.03 & 27.2 & 28.2 & 28.56 & 28.74 & 29.14 & 26.16 & 24.14 & & & & \\
\hline 13 & Pentadecane & 1504 & 1500 & 12.5 & 10 & 12 & 11.98 & 24.93 & 10.6 & 18.01 & 10.33 & 9.09 & 12.47 & 8.78 & & & & \\
\hline 14 & Germacrone & 1673 & 1693 & 1 & - & 0.45 & - & 1 & - & - & - & - & - & - & & & & \\
\hline 15 & Ethyl $p$-Methoxycinnamate & 1769 & 1760 & 21.1 & 27 & 26 & 19.58 & 17.66 & 24.56 & 10.7 & 23.54 & 17.87 & 20.14 & 18.14 & & & & 56 \\
\hline
\end{tabular}


Table 3. Cont.

\begin{tabular}{|c|c|c|c|c|c|c|c|c|c|c|c|}
\hline \multirow{3}{*}{ S1 No. } & \multicolumn{11}{|c|}{ (c) } \\
\hline & \multirow{2}{*}{ Compound } & \multirow{2}{*}{$\mathbf{R I}^{\mathrm{a}}$} & \multirow{2}{*}{$\mathbf{R I}^{\mathbf{b}}$} & \multicolumn{8}{|c|}{ Assam } \\
\hline & & & & K.g10 & K.g19 & K.g20 & K.g31 & K.g32 & K.g33 & K.g34 & K.g35 \\
\hline 1 & $\alpha$-Pinene & 932 & 932 & 1.72 & 1 & 1 & 1.2 & 1.45 & 2.1 & 1.98 & 1.1 \\
\hline 3 & $\beta$-Pinene & 977 & 974 & 1.01 & 1.23 & 1.14 & 1.01 & 1.15 & 1.31 & 1.16 & 1.2 \\
\hline 4 & $\delta$-Carene & 1011 & 1008 & 11.76 & 10.5 & 9.87 & 11.2 & 7.1 & 8.13 & 9.45 & 10.13 \\
\hline 5 & $p$-Cymene & 1021 & 1020 & - & - & 0.43 & - & 0.21 & 0.16 & 0.31 & 1.9 \\
\hline 6 & $o$-Cymene & 1023 & 1022 & 1.07 & 1.1 & 1.01 & 1.09 & 1.21 & 1.16 & 1.31 & 1.9 \\
\hline 7 & Limonene & 1028 & 1024 & 1.08 & 1.19 & 1 & 1.03 & 1.16 & 1.31 & 1.22 & 1.7 \\
\hline 9 & Borneol & 1170 & 1165 & 1.6 & 1.6 & 1.46 & 1.24 & 1.31 & 1.65 & 1.76 & 1.58 \\
\hline 10 & $\alpha$-Terpinyl Acetate & 1350 & 1346 & - & 0.4 & 0.23 & 1 & 0.89 & 0.67 & 0.22 & - \\
\hline 11 & $\alpha$-Gurjunene & 1402 & 1409 & 1.56 & 1.01 & 1.23 & 1 & 1 & 1.14 & 1.09 & 1.2 \\
\hline 12 & Ethyl Cinnamate & 1467 & 1465 & 24.9 & 25.8 & 23.89 & 23.2 & 24.17 & 21.54 & 25.02 & 26 \\
\hline 13 & Pentadecane & 1504 & 1500 & 14.52 & 10.12 & 11.54 & 13.1 & 12.46 & 11.24 & 8.14 & 12.1 \\
\hline 14 & Ethyl $p$-Methoxycinnamate & 1769 & 1760 & 22.21 & 18.14 & 20.14 & 19.2 & 20.14 & 19.43 & 17.16 & 19.1 \\
\hline
\end{tabular}

${ }^{a}$ RI, Retention indices on Elite-5 column, experimentally determined using homologous series of C8-C20 n-alkanes. ${ }^{\mathrm{b}}$ RI; Retention index taken from literature [30]. 


\subsection{Statistical Analysis}

To establish a correlation among different accessions with respect to quality constituents, agglomerative hierarchical clustering (AHC) and principal component analysis (PCA) were performed using the Minitab statistical software. According to the AHC analysis, the dendrogram group I represents the Odisha province accessions, whereas groups II and III represent the West-Bengal and Assam province accessions, respectively (Figure 5).

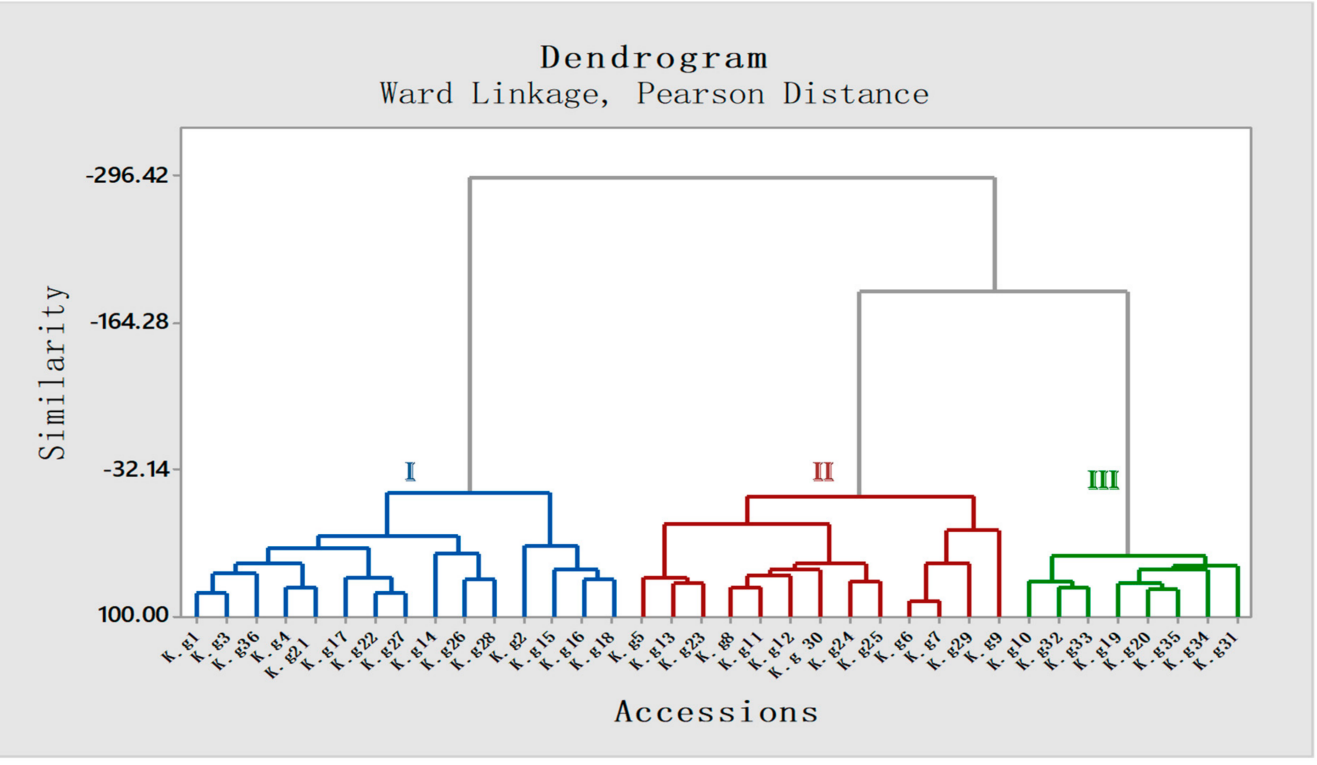

Figure 5. Agglomerative hierarchical clustering (AHC) based dendrogram of 36 accessions of $K$. galanga based on Ward Linkage (Pearson distance). All 36 accessions have been distributed into 3 clusters on the basis of similarity in area percentage of constituents among different accessions. Cluster I: Odisha, Cluster II: West-Bengal, Cluster III: Assam (III).

To further validate the result, PCA analysis was employed, which categorized all 36 accessions into three different groups according to different province (Figure 6). The regions of West-Bengal and Assam fell sharply in two different quadrants, whereas accessions from Odisha share another quadrant with slight deviations of a few constituents. This may be due to the collection of samples from diverse eco-regions of Odisha (Figure 6).

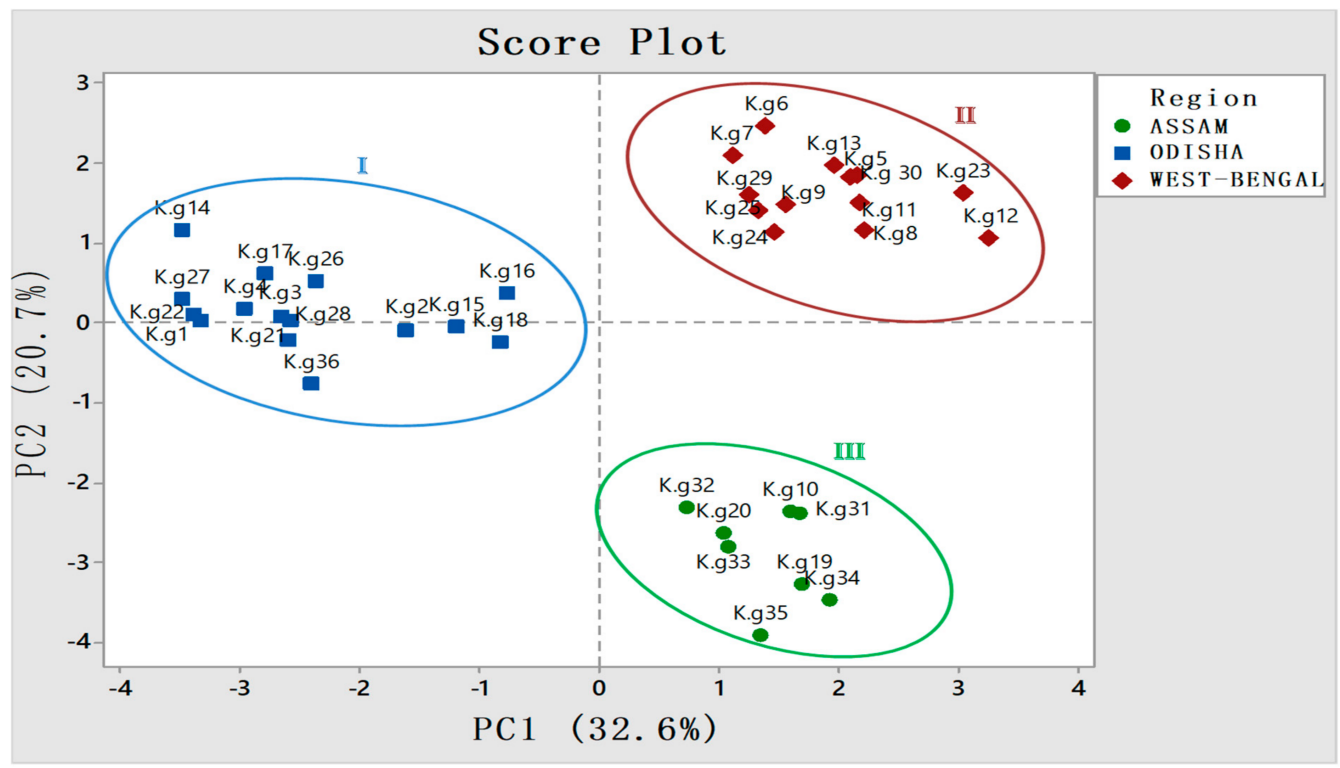

Figure 6. Three different provinces and their respective accessions falling into different quadrants in score plot of principal component analysis (PCA) showing significant diversity w.r.t constituents having area $\% \geq 1$. 
The PCA analysis biplot presented the constituents responsible for the variations among 36 accessions of three provinces (Figure 7). The key constituents responsible for the variation in Odisha province are EPMC (20.14- 41.1\%), germacrene D (1-1.9\%), and limonene (1-2.1\%). In West Bengal $p$-cymene (1-1.42\%), $\alpha$-terpinyl acetate $(0.12-1.08 \%)$, were mostly responsible for the variation from the other two provinces. Similarly, in Assam accessions compounds like $o$-cymene (1.01-1.9\%), $\beta$-pinene $(1.01-1.31 \%)$, and $\alpha$ gurjunene $(1-1.56 \%)$ have been identified as responsible for the variations among the other two provinces.

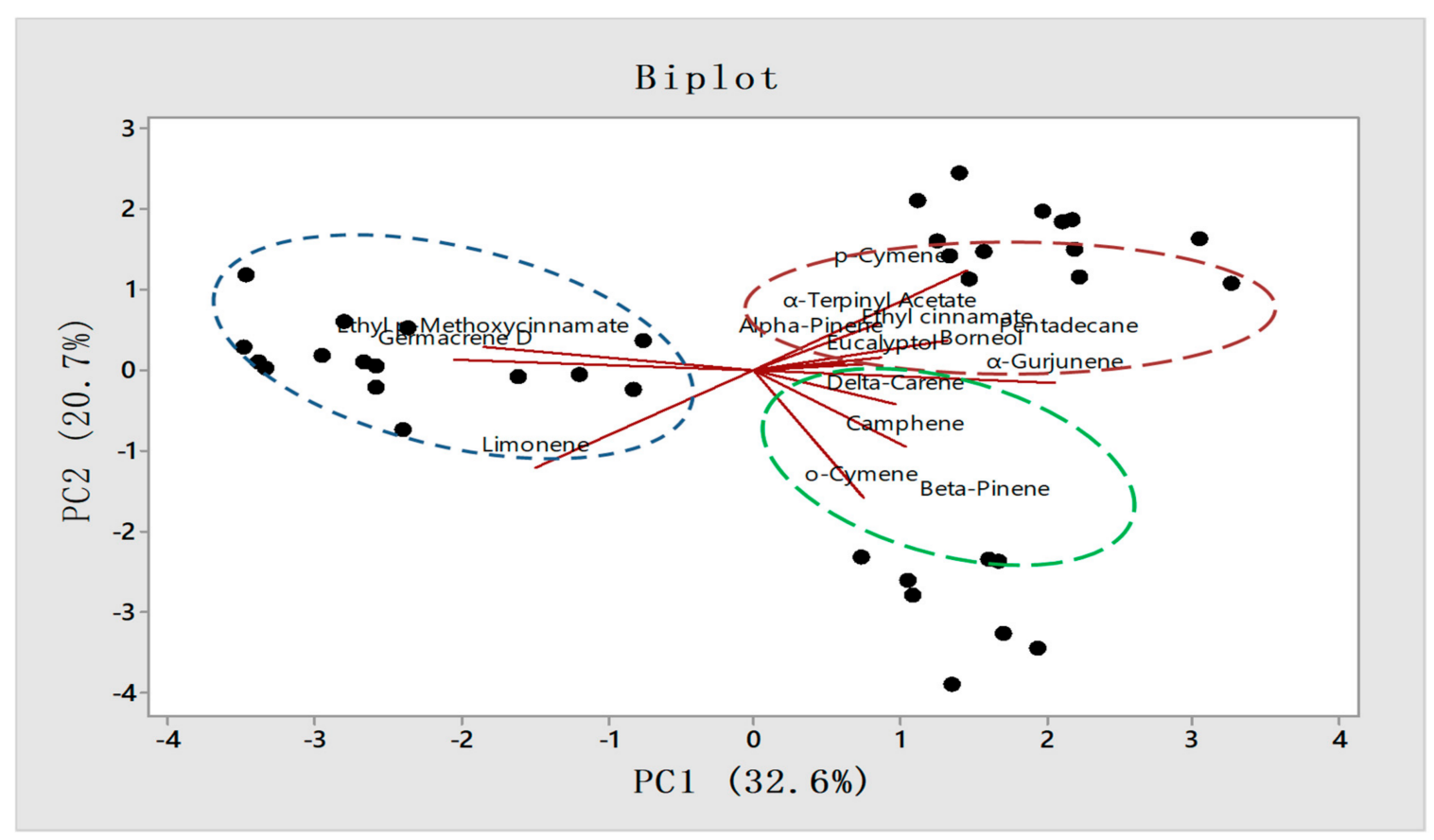

Figure 7. PCA Biplot graph representing individual constituents responsible for the variation among provinces.

The variations obtained in phyto-constituents are quite natural as these accessions have been taken from different geographical regions. Due to their different geographical regions, the species are exposed to different exogenous factor-related stresses which lead to the production of different secondary metabolites for their defense [40]. Several reports in other species are also available in which variation in constituents was discussed for different eco-regions [35,36]. Identifying a single parameter responsible for such variations is a very cumbersome process as collective exogenous factors such as soil, $\mathrm{pH}$, altitude, growing site precipitation, etc. may be responsible for such variations as discussed by other researchers [22,29]. All these parameters may not be present at a single region, which leads to variation in essential oil yield and its constituents. PCA and AHC were used for the first time as pattern recognizing methods to study the chemical diversity analysis of K. galanga essential oil. This approach it has also been successfully employed to analyze the correlation and variation in different crops [35,36,41].

\section{Conclusions}

It can be concluded from the current study that there are variations in the yield and chemical composition of different $K$. galanga accessions collected from Odisha, WestBengal, and Assam provinces of India. The impact of environmental factors of different geographical regions may be the possible reason to account for the observed variations in essential oil yield and quality constituents. All these accessions were characterized by a maximum amount of phenyl polypropanoids, which were cinnamic acid esters. Two chemovars obtained in this study (K.g16 and K.g14) with highest essential oil yield 
and quality constituent could be utilized for large scale cultivation with a view towards industrial utilization.

Supplementary Materials: The following are available online. Table S1 (a) Chemical profiling of Kaempferia galanga rhizome essential oil collected from different provinces of Odisha, (b) Chemical profiling of Kaempferia galanga rhizome essential oil collected from different provinces of West-Bengal, (c) Chemical profiling of Kaempferia galanga rhizome essential oil collected from different provinces of Assam. Table S2. Chemical Structure of all identified constituents from K. galanga rhizome essential oil. Figure S1. Authentic identification of EC and EPMC constituents in analytes by co-injecting with known standards through GC-MS. (a): Chromatogram of EC standard (b): Consensus GC-MS fingerprint of $K$. galanga accessions collected from three different provinces showing similar pattern. (c): Chromatogram of EPMC standard.

Author Contributions: Conceptualization, B.K. and S.S. (Suprava Sahoo); methodology, M.D., S.S. (Subhashree Singh); software, (Subhashree Singh), B.C.S.; validation, S.S. (Subhashree Singh) and S.S. (Suprava Sahoo); formal analysis, S.S. (Subhashree Singh), M.D.; investigation, S.S. (Subhashree Singh), B.K. and S.S. (Suprava Sahoo); Resources, M.D., S.S. (Subhashree Singh) and B.C.S.; data curation, S.S. (Subhashree Singh), B.K.; writing-original draft preparation, S.S. (Subhashree Singh); writing-review and editing, B.K., B.C.S. and S.N.; visualization, S.S. (Subhashree Singh), B.K. and S.S. (Suprava Sahoo); supervision, B.K.; project administration, B.K. All authors have read and agreed to the published version of the manuscript.

Funding: This research received no external funding.

Institutional Review Board Statement: Not applicable.

Informed Consent Statement: Not applicable.

Data Availability Statement: Not applicable.

Acknowledgments: We are thankful to Manoj Ranjan Nayak and S.C. Si for their constant support and encouragement in and out of the centre. The work would not have been easy without the help of P.C. Panda (taxonomist, Center for Biotechnology, Siksha 'O' Anusandhan Deemed to be University, Bhubaneswar) for authenticating the samples.

Conflicts of Interest: The authors declare no conflict of interest.

\section{References}

1. Ochuthressia, K.; Britto, S.J.; Jaseentha, M.O.; Raphael, R. In vitro antimicrobial evaluation of Kaempferia galanga L. rhizome extract. Am. J. Biotechnol. Mol. Sci. 2012, 2, 1-5. [CrossRef]

2. Indrayan, A.K.; Kurian, A.; Tyagi, P.K.; Shatru, A.; Rathi, A.K. Comparative chemical study of two varieties of attractive medicinal plant Kaempferia galanga Linn. Indian J. Nat. Prod. Resour. 2007, 6, 327-333.

3. Mitra, R.; Orbell, J.; Muralitharan, M.S. Agriculture-Medicinal Plants of Malaysia. Asia Pac. Biotech News 2007, 11, 105-110. [CrossRef]

4. Techaprasan, J.; Klinbunga, S.; Ngamriabsakul, C.; Jenjittikul, T. Genetic variation of Kaempferia (Zingiberaceae) in Thailand based on chloroplast DNA (psbA-trnH and petA-psbJ) sequences. Genet. Mol. Res. 2010, 9, 1957-1973. [CrossRef] [PubMed]

5. Othman, R.; Ibrahim, H.; Mohd, M.A.; Mustafa, M.R.; Awang, K. Bioassay-guided isolation of a vasorelaxant active compound from Kaempferia galanga L. Phytomedicine 2006, 13, 61-66. [CrossRef] [PubMed]

6. Huang, L.; Yagura, T.; Chen, S. Sedative activity of hexane extract of Keampferia galanga L. and its active compounds. J. Ethnopharmacol. 2008, 120, 123-125. [CrossRef] [PubMed]

7. Sukari, M.A.; Mohd, S.; Yap, A.L.C.; Tang, S.W.; Neoh, B.K.; Rahmani, M.; Ee, G.C.L.; Taufiq-Yap, Y.H.; Yusof, U.K. Chemical constituent variations of essential oils from rhizomes of four Zingiberaceae species. Malays. J. Anal. Sci. 2008, 12, 638-644.

8. Liu, B.; Liu, F.; Chen, C.; Gao, H. Supercritical carbon dioxide extraction of ethyl p-methoxycinnamate from Kaempferia galanga L. rhizome and its apoptotic induction in human HepG2 cells. Nat. Prod. Res. 2010, 24, 1927-1932. [CrossRef]

9. Hong, T.K.; Kim, S.I.; Heo, J.W.; Lee, J.K.; Choi, D.R.; Ahn, Y.J. Toxicity of Kaempferia galanga rhizome constituents of Meloidogyne incognita juveniles and egg. Nematology 2011, 13, 235-244. [CrossRef]

10. Kumar, A. Chemical composition of essential oil isolated from the rhizomes of Kaempferia galanga L. Int. J. Pharma Bio. Sci. 2014, 5, 225-231.

11. Sivarajan, V.V.; Balachandran, I. Ayurvedic Drugs and Their Plant Sources; Oxford and IBH Publishing Co. Pvt. Ltd.: New Delhi, India, 1994; pp. 374-376.

12. Othman, R.; Ibrahim, H.; Mohd, M.A.; Awang, K.; Gilani, A.U.H.; Mustafa, M.R. Vasorelaxant effects of ethyl cinnamate isolated from Kaempferia galanga on smooth muscles of the rat aorta. Planta Med. 2002, 68, 655-657. [CrossRef] [PubMed] 
13. Raina, A.P.; Abraham, Z.; Sivaraj, N. Diversity analysis of Kaempferia galanga L. germplasm from South India using DIVA-GIS approach. Ind. Crop. Prod. 2015, 69, 433-439. [CrossRef]

14. Kosuge, T.; Yokta, M.; Sugiyama, K.; Saito, M.; Iwata, Y.; Nakkura, M.; Yamamoto, T. Studies on anticancer principles in Biota orientalis and Kaempferia galanga. Chem. Pharm. Bull. 1985, 33, 5565-5567. [CrossRef]

15. Xue, Y.; Chen, H. Study on the anti-carcinogenic effects of three compounds in Kaempferia galanga L. Wei Sheng Yan Jiu 2002, 31, 247-248. [PubMed]

16. Lakshmanan, D.; Werngren, J.; Jose, L.; Suja, K.P.; Nair, M.S.; Varma, R.L.; Mundayoor, S.; Hoffner, S.; Kumar, R.A. Ethyl p-methoxycinnamate isolated from a traditional anti-tuberculosis medicinal herb inhibits drug resistant strains of Mycobacterium tuberculosis in vitro. Fitoterapia 2011, 82, 757-761. [CrossRef]

17. Preetha, T.S.; Kumar, A.S.H.; Krishnan, P.N. A comprehensive review of Kaempferia galanga L. (Zingiberaceae): A high sought medicinal plant in Tropical Asia. J. Med. Plants Stud. 2016, 4, 270-276.

18. Jena, S.; Ray, A.; Banerjee, A.; Sahoo, A.; Nasim, N.; Sahoo, S.; Kar, B.; Patnaik, J.; Panda, P.C.; Nayak, S. Chemical composition and antioxidant activity of essential oil from leaves and rhizomes of Curcuma angustifolia Roxb. Nat. Prod. Res. 2017, 31, 2188-2191. [CrossRef]

19. Nasim, N.; Behera, J.K.; Sandeep, I.S.; RamaRao, V.V.; Kar, B.; Mishra, A.; Nayak, S.; Mohanty, S. Phytochemical analysis of flower from Pandanus odorifer (Forssk.) Kuntze for industrial application. Nat. Prod. Res. 2018, 32, 2494-2497. [CrossRef]

20. Singh, S.; Sahoo, S.; Ray, A.; Sahoo, A.; Nayak, S.; Kar, B. Thermal desorption modulation based detection of volatile constituents of Alpinia galanga by two dimensional gas chromatography and time of flight mass spectrometry. Nat. Prod. Res. 2019, 35, 512-516. [CrossRef] [PubMed]

21. Sahoo, S.; Singh, S.; Dash, M.; Jena, S.; Sahoo, A.; Nayak, S.; Kar, B. Electron Ionization Based Detection of Volatile Constituents of Aerial Parts of Eclipta prostrata (Linn.) by One Dimensional Gas Chromatography and Mass Spectrometry. J. Essent. Oil Bear. Plants 2020, 23, 559-566. [CrossRef]

22. Singh, S.; Sahoo, B.C.; Ray, A.; Jena, S.; Dash, M.; Nayak, S.; Kar, B.; Sahoo, S. Intraspecific Chemical Variability of Essential Oil of Curcuma caesia (Black Turmeric). Arab. J. Sci. Eng. 2020, 46, 191-198. [CrossRef]

23. Mohanty, S.; Parida, R.; Singh, S.; Joshi, R.K.; Subudhi, E.; Nayak, S. Biochemical and molecular profiling of micropropagated and conventionally grown Kaempferia galanga. Plant Cell Tissue Organ Cult. 2011, 106, 39-46. [CrossRef]

24. Sahoo, S.; Parida, R.; Singh, S.; Padhy, R.N.; Nayak, S. Evaluation of yield, quality and antioxidant activity of essential oil of in vitro propagated Kaempferia galanga Linn. J. Acute Dis. 2014, 3, 124-130. [CrossRef]

25. Li, Y.C.; Ji, H.; Li, X.H.; Zhang, H.X.; Li, H.T. Isolation of nematicidal constituents from essential oil of Kaempferia galanga L. rhizome and their activity against Heteroderaavenae Wollenweber. Trop. J. Pharm. Res. 2017, 16, 59-65. [CrossRef]

26. Lal, M.; Munda, S.; Dutta, S.; Baruah, J.; Pandey, S.K. Identification of the new high oil and rhizome yielding variety of Kaempferia galanga (Jor Lab K-1): A highly important indigenous medicinal plant of North East India. J. Essent. Oil Bear. Plants 2017, 20, 1275-1282. [CrossRef]

27. Swapna, T.S.; Binitha, M.; Manju, T.S. In vitro multiplication in Kaempferia galanga Linn. Appl. Biochem. Biotechnol. 2004, 118, 233-241. [CrossRef]

28. Batugal, P.A.; Kanniah, J.; Sy, L.; Oliver, J.T. Medicinal Plants Research in Asia-Volume I: The Framework and Project Workplans; Bioversity International: Rome, Italy, 2004.

29. Lim, T.K. Kaempferia galanga. In Edible Medicinal and Non-Medicinal Plants; Springer: Cham, Switzerland, 2016; Volume 12, pp. $417-435$.

30. Adams, R.P. Identification of Essential Oil Components by Gas Chromatography/Mass Spectroscopy; Allured Publishing Corporation: Carol Stream, IL, USA, 2007.

31. Ward, J.H., Jr. Hierarchical grouping to optimize an objective function. J. Am. Stat. Assoc. 1963, 58, 236-244. [CrossRef]

32. Abdi, H.; Williams, L.J. Principal component analysis. Wiley Interdiscip. Rev. Comput. Stat. 2010, 2, 433-459. [CrossRef]

33. Wong, K.C.; Ong, K.S.; Lim, C.L. Compositon of the essential oil of rhizomes of Kaempferia galanga L. FlavourFragr. J. 1992, 7, 263-266. [CrossRef]

34. Figueiredo, A.C.; Barroso, J.G.; Pedro, L.G.; Scheffer, J.J. Factors affecting secondary metabolite production in plants: Volatile components and essential oils. FlavourFragr. J. 2008, 23, 213-226. [CrossRef]

35. Ray, A.; Jena, S.; Dash, B.; Kar, B.; Halder, T.; Chatterjee, T.; Ghosh, B.; Panda, P.C.; Nayak, S.; Mahapatra, N. Chemical diversity, antioxidant and antimicrobial activities of the essential oils from Indian populations of Hedychium coronarium Koen. Ind.CropsProd. 2018, 112, 353-362. [CrossRef]

36. Dash, B.; Ray, A.; Sahoo, A.; Kar, B.; Chatterjee, T.; Halder, T.; Chandra Panda, P.; Patnaik, J.; Ghosh, B.; Nayak, S. A combined approach using ISSR and volatile compound analysis for assessment of genetic and phytochemical diversity in Zingiber zerumbet (1.) from eastern India. J. Essent. Oil Bear. Plants 2019, 22, 31-49. [CrossRef]

37. Sandeep, I.S.; Sahoo, B.C.; Singh, S.; Sahoo, S.; Nayak, S.; Kar, B. Environmental Factors Influencing Yield and Quality of Essential Oils in Curcuma longa cv. Lakadong. Proc. Natl. Acad. Sci. India Sect. B Biol. Sci. 2021, 91, 761-767. [CrossRef]

38. Rao, V.K.; Rajasekharan, P.E.; Roy, T.K.; Kumar, T.V. Comparison of essential oil components in rhizomes and in-vitro regenerated whole plants of Kaempferia galanga L. J. Med. Arom. Plant Sci. 2009, 31, 326-329.

39. Kumar, A. Phytochemistry, pharmacological activities and uses of traditional medicinal plant Kaempferia galanga L.-An overview. J. Ethnopharmacol. 2020, 253, 112667. [CrossRef] 
40. Barra, A. Factors affecting chemical variability of essential oils: A review of recent developments. Nat. Prod. Commun. 2009, 4, 1147-1154. [CrossRef] [PubMed]

41. Ray, A.; Jena, S.; Kar, B.; Sahoo, A.; Panda, P.C.; Nayak, S.; Mahapatra, N. Volatile metabolite profiling of ten Hedychium species by gas chromatography mass spectrometry coupled to chemometrics. Ind. Crop. Prod. 2018, 126, 135-142. [CrossRef] 